\title{
Wall teichoic acids mediate increased virulence in Staphylococcus aureus
}

\author{
Stefanie Wanner ${ }^{1 \dagger}$, Jessica Schade ${ }^{1 \dagger}$, Daniela Keinhörster ${ }^{1}$, Nicola Weller', Shilpa E. George ${ }^{1}$, \\ Larissa Kull', Jochen Bauer1, Timo Grau1, Volker Winstel2, Henriette Stoy', Dorothee Kretschmer', \\ Julia Kolata ${ }^{3}$, Christiane Wolz', Barbara M. Bröker ${ }^{4}$ and Christopher Weidenmaier ${ }^{1,5 \star}$
}

\begin{abstract}
Community-associated methicillin-resistant Staphylococcus aureus (CA-MRSA) are the cause of a severe pandemic consisting primarily of skin and soft tissue infections. The underlying pathomechanisms have not been fully understood and we report here a mechanism that plays an important role for the elevated virulence of CA-MRSA. Surprisingly, skin abscess induction in an animal model was correlated with the amount of a major cell wall component of S. aureus, termed wall teichoic acid (WTA). CA-MRSA exhibited increased cell-wall-associated WTA content (WTA ${ }^{\text {high }}$ ) and thus were more active in inducing abscess formation via a WTA-dependent and T-cell-mediated mechanism than S. aureus strains with a WTA ${ }^{\text {low }}$ phenotype. We show here that WTA is directly involved in S. aureus strain-specific virulence and provide insight into the underlying molecular mechanisms that could guide the development of novel anti-infective strategies.
\end{abstract}

ommunity-associated methicillin-resistant Staphylococcus aureus (CA-MRSA) strains pose a serious threat due to their rapid epidemic spread and their enormous virulence potential, which exceeds that of traditional hospital-associated strains (HA-MRSA) ${ }^{1}$. Skin and soft tissue infections (SSTIs) are the most common CA-MRSA infections, and $50-75 \%$ of patients present with abscesses ${ }^{2}$. Less frequent are lethal infections such as sepsis or necrotizing pneumonia ${ }^{3-7}$. In the USA, USA300 isolates are primarily responsible for the ongoing CA-MRSA epidemics $^{8-10}$, having replaced earlier USA400 isolates ${ }^{11}$. The success of CA-MRSA strains appears to be due to a unique combination of genetic factors that enable the bacteria to evade the human host defence systems ${ }^{12-18}$. However, the relative role of virulence factors in CA-MRSA virulence is still under debate ${ }^{19-22}$. More recent findings suggest that the cytolytic phenol-soluble modulin PSMa peptides ${ }^{23-25}$, which are responsible for increased neutrophil killing capacity, the cytolysin $\alpha$-toxin ${ }^{20,24,26,27}$, as well as the global virulence regulator (termed accessory gene regulator $(\mathrm{Agr})^{28}$ ) play key roles in CA-MRSA virulence in different experimental skin infection models. It has been demonstrated that the global virulence gene regulator Agr exerts strict control over PSM expression ${ }^{29}$ and that the cytolytic PSMa peptides are produced in large amounts by CA-MRSA strains ${ }^{23,30}$ as a consequence of high Agr activity ${ }^{30}$. The agr four-gene operon encodes a typical autoactivation circuit $^{31}$ and makes use of a regulatory RNA, RNAIII, as its effector ${ }^{32,33}$. In this study, we present evidence for a novel important factor in CA-MRSA virulence. Until now the focus has largely been on toxins and a putative pathogenicity island termed the 'arginine catabolic mobile element' (ACME) $)^{34-36}$. However, the impact of cell wall components has not been studied so far. Here, we introduce a novel concept of staphylococcal strain-specific virulence that includes a major cell wall glycopolymer. Cell wall teichoic acid (WTA) is a zwitterionic, secondary cell wall polymer of $S$. aureus that has important functions in bacterial physiology $y^{37}$ as well as in $S$. aureus colonization and infection ${ }^{38-41}$. WTA is one of the most abundant surface determinants of $S$. aureus and has recently attracted major attention as a target structure for novel anti-infective strategies $^{42}$ and antibiotics ${ }^{43-48}$. The WTA of $S$. aureus is composed of $\sim 40$ ribitol phosphate repeating units modified with $\mathrm{N}$-acetylglucosamine and D-alanine $\mathrm{e}^{49,50}$ (Supplementary Fig. 1). Negatively charged phosphate groups in the repeating unit and ester-linked D-alanine residues are responsible for the zwitterionic charge of WTA. We have demonstrated previously that the zwitterionic WTA of $S$. aureus activates $\mathrm{CD} 4^{+} \mathrm{T}$ cells via a major histocompatibility complex (MHC) II-dependent mechanism, which modulates the development of skin abscesses in a mouse model ${ }^{51}$ at the early stages of abscess formation. Given that CA-MRSA is the predominant cause of SSTIs, we focus here on the role of WTA in CA-MRSA skin infections and demonstrate that the WTA content in cell wall fractions from highly pathogenic CA-MRSA strains such as USA300 (LAC) and MW2 (USA400) is significantly elevated compared to less virulent patient isolates (103), HA-MRSA (USA500) or laboratory strains (SA113). We termed these phenotypes WTA ${ }^{\text {high }}$ and $\mathrm{WTA}^{\text {low }}$, respectively, and describe here the underlying regulatory mechanisms and the impact on skin-infection-related virulence in a mouse model.

\section{Results}

Highly pathogenic CA-MRSA strains exhibit elevated WTA content in their cell walls compared to less pathogenic strains. We analysed the cell wall composition of several $S$. aureus strains that share the same ribitol-WTA structure and biosynthetic pathways (Supplementary Figs 1-3) with respect to amounts of WTA. When we determined the WTA content of the cell wall fractions, we found that the highly pathogenic CA-MRSA strains MW2 and USA300, as well as clinical isolate 103 (superantigen-free,

\footnotetext{
'Department of Medicine, Interfacultary Institute for Microbiology and Infection Medicine (IMIT), University of Tübingen, Elfriede-Aulhorn Straße 6, 72076 Tübingen, Germany. ${ }^{2}$ Department of Microbiology, University of Chicago, Chicago, Illinois 60637, USA. ${ }^{3}$ Medical Microbiology, UMC Utrecht, Heidelberglaan 100, 3584CX Utrecht, The Netherlands. ${ }^{4}$ Department of Immunology, University Medicine Greifswald, Ferdinand-Sauerbruch-Straße DZ7, 17475 Greifswald, Germany. ${ }^{5}$ German Center for Infection Research (DZIF), Partner Site Tübingen, 72076 Tübingen, Germany. ${ }^{\dagger}$ These authors contributed equally to this work. ${ }^{\star}$ e-mail: christopher.weidenmaier@med.uni-tuebingen.de
} 


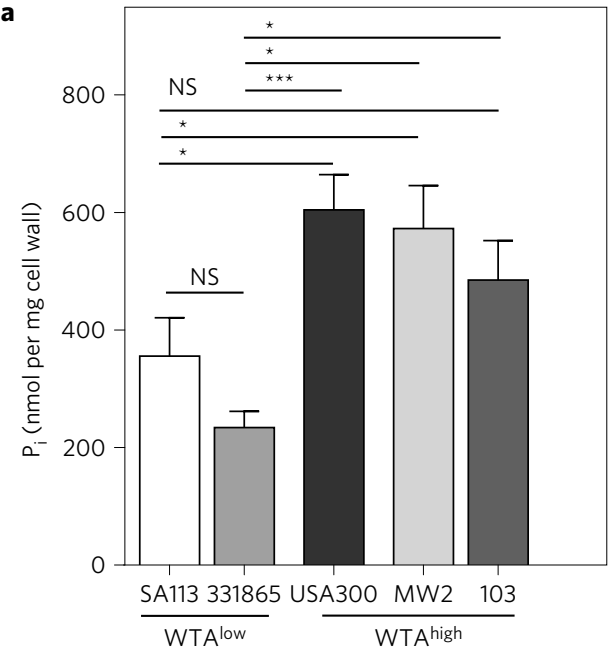

b

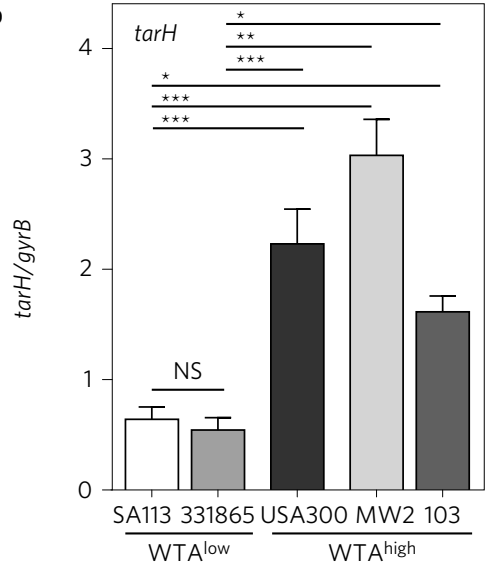

c

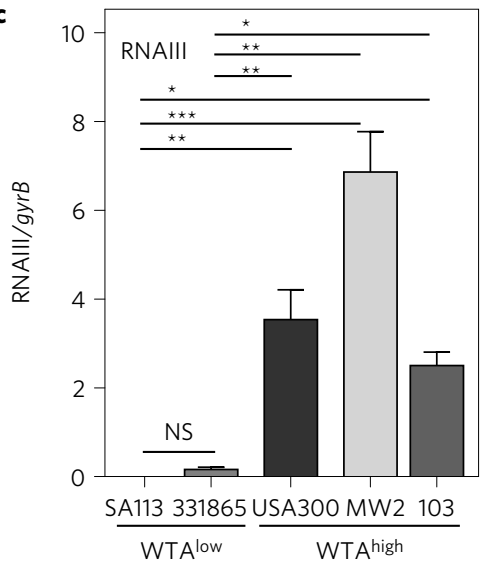

d

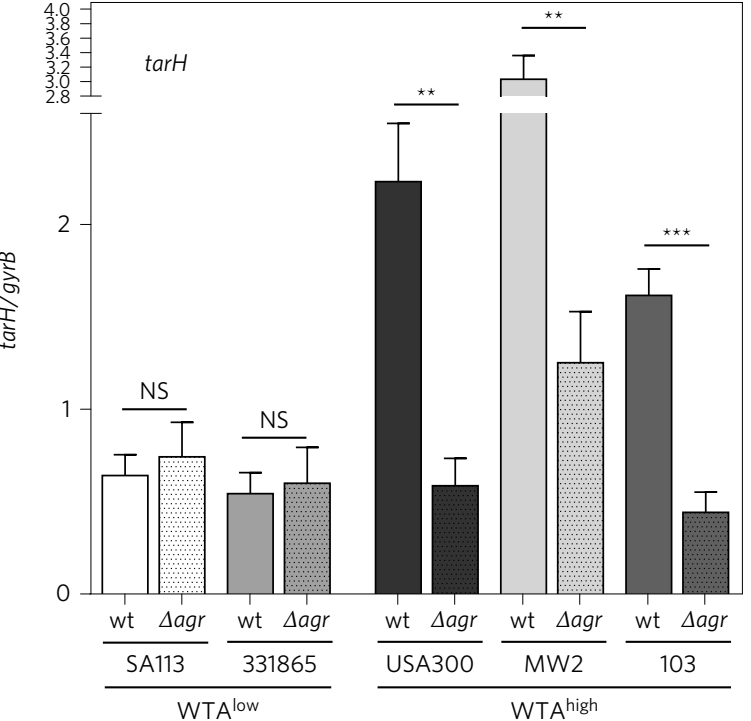

Figure 1 | Amounts of WTA in the cell wall fractions of $S$. aureus strains and transcriptional analysis by qRT-PCR. a, The amount of WTA per mg of cell wall preparation was determined with a colorimetric assay and is depicted as nmol inorganic phosphorus $\left(P_{i}\right)$ per mg cell wall dry weight. CA-MRSA strains USA300 and MW2 (as well as clinical, superantigen-free isolate 103) were compared to non-CA-MRSA strains (SA113, and clinical, superantigen-free isolate 331865). Shown are means \pm s.e.m. for $n=8-11$ independent WTA isolations. $P$ values for multiple comparisons were determined by one-way ANOVA with Tukey's post-test. ${ }^{\star} P<0.05,{ }^{\star \star} P<0.01,{ }^{\star \star \star} P<0.0001$. NS, not significant. $\mathbf{b}$, Transcriptional analysis of the WTA biosynthesis gene tarH from in vitro cultures grown to stationary phase in WTA ${ }^{\text {high }}$ strains $\left(M W 2\right.$, USA300, 103) and WTA ${ }^{\text {low }}$ strains (SA113, 331865). The expression of transcripts was quantified relative to the transcription of gyrase (copies of $\operatorname{tarH}$ per copy of $g y r B$ ). Shown are means \pm s.e.m., $n=6$ independent experiments. $P$ values for multiple comparisons were determined by one-way ANOVA with Tukey's post-test. ${ }^{\star} P<0.05$, ${ }^{\star \star} P<0.01$, ${ }^{\star \star \star} P<0.0001$. c, Transcriptional analysis of RNAIII, the downstream regulator of the global virulence Agr regulon. WTA ${ }^{\text {high }}$ strains (MW2, USA300, 103) and WTA ${ }^{\text {low }}$ strains (SA113, 331865) were grown to stationary phase. Transcripts were quantified relative to the transcription of gyrase (copies of RNAlll per copy of gyrB). Shown are means \pm s.e.m., $n=6$ independent experiments. $P$ values for multiple comparisons were determined by one-way ANOVA with Tukey's post-test. ${ }^{\star} P<0.05,{ }^{\star \star} P<0.01$, ${ }^{\star \star \star} P<0.0001$. d, Transcriptional analysis of the WTA biosynthesis gene tarH. In vitro cultures of WTA ${ }^{\text {high }}$, WTA ${ }^{\text {high }} \Delta a g r$ mutant, WTA ${ }^{\text {low }}$ and WTA ${ }^{\text {low }} \Delta a g r$ mutant strains were grown to stationary phase. Transcripts were quantified relative to the transcription of gyrase (copies of tarH per copy of gyrB). Shown are means \pm s.e.m., $n=6$ independent experiments. Statistically significant differences between WTA ${ }^{\text {high }}$ and WTA ${ }^{\text {low }}$ and their respective $\Delta a g r$ mutant strains were determined by Student's $t$-test. ${ }^{\star} P<0.05,{ }^{\star \star} P<0.01,{ }^{\star \star \star} P<0.001$.

included as a control for superantigen activity; see section beginning with 'Cell wall fractions'), exhibited elevated WTA content in their cell wall fractions compared to laboratory strain SA113 and clinical isolate 331865 (superantigen-free, included as a control for superantigen activity). We grouped the isolates as WTA ${ }^{\text {high }}$ (MW2, USA300, 103) and WTA ${ }^{\text {low }}$ (SA113, 331865) strains (Fig. 1a).

The WTA ${ }^{\text {high }}$ phenotype is mediated by overexpression of the tarH gene. To understand the mechanisms underlying the $\mathrm{WTA}^{\text {high }}$ and $\mathrm{WTA}^{\text {low }}$ phenotypes, we quantified the expression of genes involved in WTA biosynthesis using quantitative realtime-polymerase chain reaction (qRT-PCR) of in vitro cultures. The WTA biosynthesis genes $\operatorname{tarO}, \operatorname{tar} A, \operatorname{tar} K, \operatorname{tar} L, \operatorname{tar} G$ and
tarH (Supplementary Figs 2 and 3) were analysed in the logarithmic and stationary growth phases (Fig. 1 and Supplementary Figs 4 and 5). Only tarH transcription was significantly increased in WTA $^{\text {high }}$ strains (MW2, USA300, 103) compared to WTA ${ }^{\text {low }}$ strains (SA113, 331865). This effect was only observed in the stationary growth phase (Fig. 1b) (transcriptional analyses for tarH in logarithmic and tarO, tarA in stationary and logarithmic growth phases are shown in Supplementary Fig. 4, and for tarK and tarL in Supplementary Fig. 5a,b, respectively). $\operatorname{tar} H$ encodes for the energizing part of the two-component ABC transporter (TarGH), which facilitates WTA translocation across the membrane $e^{52,53}$. Because we detected decreased tarK expression in MW2, we also analysed a potential 

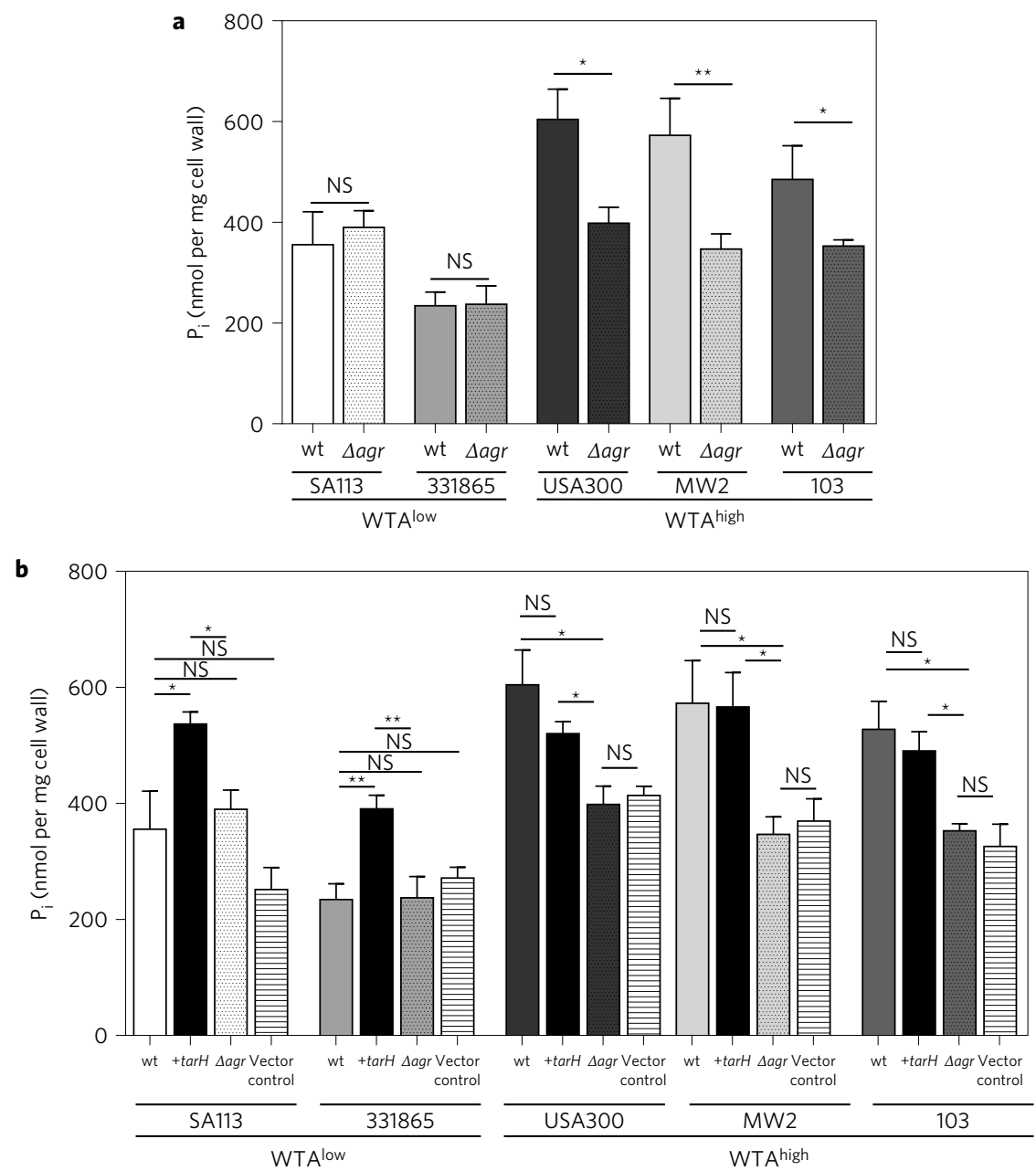

Figure 2 | Agr-dependent control of WTA content in the staphylococcal cell wall. a, Content of WTA in the cell wall of WTA ${ }^{\text {high }}$ (MW2, USA300, 103),

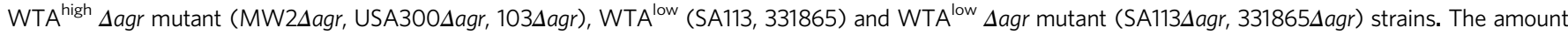
of WTA per mg cell wall preparation was determined with a colorimetric assay (WTA amount is depicted as nmol inorganic phosphorus $\left(P_{i}\right)$ per mg cell wall dry weight). Shown are means \pm s.e.m. for $n=8-11$ independent WTA isolations. Statistically significant differences between WTA ${ }^{\text {high }}$ and WTA ${ }^{\text {low }}$ and their respective $\Delta$ agr mutant strains were determined by Student's $t$-test. ${ }^{\star} P<0.05,{ }^{\star \star} P<0.01,{ }^{\star \star \star} P<0.001$. $\mathbf{b}$, Content of WTA in the cell wall fractions of WTA ${ }^{\text {high }}$, WTA ${ }^{\text {high }} \Delta$ agr mutant and WTA ${ }^{\text {low }}$ strains after tarH overexpression. Overexpression of tarH in expression vector pRB474 (under control of a constitutive promoter) was tested in WTA ${ }^{\text {low }}$ strains SA113 and 331865. Expression vector pRB474 alone was used as a negative (vector) control. The amount of WTA per mg cell wall preparation was determined with a colorimetric assay. Shown are means \pm s.e.m. for $n=8-12$ independent WTA isolations. $P$ values for multiple comparisons were determined by one-way ANOVA with Tukey's post-test for each strain. ${ }^{\star} P<0.05,{ }^{\star \star} P<0.01,{ }^{\star \star \star} P<0.001$.

chain length variation in the WTA polymer. However, WTA PAGE analysis (Supplementary Fig. 4a) of polymer isolated from stationary-phase cells did not reveal significant differences in polymer lengths between WTA ${ }^{\text {high }}$ and $\mathrm{WTA}^{\text {low }}$ strains.

The WTA ${ }^{\text {high }}$ phenotype depends on a highly active Agr regulon. The Agr system has been linked to staphylococcal pathogenesis in a subcutaneous abscess infection model ${ }^{54}$, and is known to increase the expression of virulence factors during the transition from the late-exponential to stationary growth phase in vitro ${ }^{55,56}$. To test whether the Agr system is differentially expressed in WTA ${ }^{\text {high }}$ and $\mathrm{WTA}^{\text {low }}$ strains, we measured the expression of the primary transcript RNAIII in the stationary growth phase by qRT-PCR. All WTA ${ }^{\text {high }}$ strains possessed an intact Agr regulon and produced high levels of RNAIII. One of the WTA ${ }^{\text {low }}$ strains was a naturally occurring functional agr-deletion mutant (SA113), while the other produced low levels of RNAIII (Fig. 1c).

To test whether the agr system is involved in the differential regulation of the WTA biosynthesis gene tarH, we compared agrdeletion mutants (Supplementary Table 1) with their corresponding isogenic wild type (wt) by qRT-PCR. In WTA ${ }^{\text {high }}$ strains, tarH expression in $\Delta a g r$ mutants was significantly decreased compared to the WTA ${ }^{\text {high }}$ wt strains. In contrast, there was no difference in $\operatorname{tarH}$ expression between WTA ${ }^{\text {low }} \Delta a g r$ mutants and their wt strains (Fig. 1d).

To validate the role of Agr in WTA biosynthesis, we quantified the WTA content of WTA ${ }^{\text {high }}$ and WTA ${ }^{\text {low }}$ strains and their $\Delta a g r$ mutants with a colorimetric assay. WTA content correlated with tarH expression levels and was significantly reduced in $\mathrm{WTA}^{\text {high }} \Delta a g r$ mutants. Conversely, WTA ${ }^{\text {low }} \Delta a g r$ mutants and WTA $^{\text {low }}$ wt strains showed no difference in WTA content. WTA ${ }^{\text {high }} \Delta a g r$ mutants demonstrated the same WTA content as both wt and $\Delta a g r$ mutants in the $\mathrm{WTA}^{\text {low }}$ strain background (Fig. 2a). This is evidence for a distinct role for the Agr system in WTA biosynthesis regulation in WTA ${ }^{\text {high }}$ strains. Moreover, there appears to be a correlation between loss of Agr function and the reduced expression of $\operatorname{tar} H$ in $\mathrm{WTA}^{\text {low }}$ strains. In line with these results, we found that an HA-MRSA strain (USA 500) that exhibited low agr-activity (Supplementary Fig. 6a) also exhibited low tarH expression (Supplementary Fig. 6b) and therefore a WTA ${ }^{\text {low }}$ phenotype (Supplementary Fig. 6c) when compared to WTA ${ }^{\text {high }}$ CA-MRSA strain USA300. 

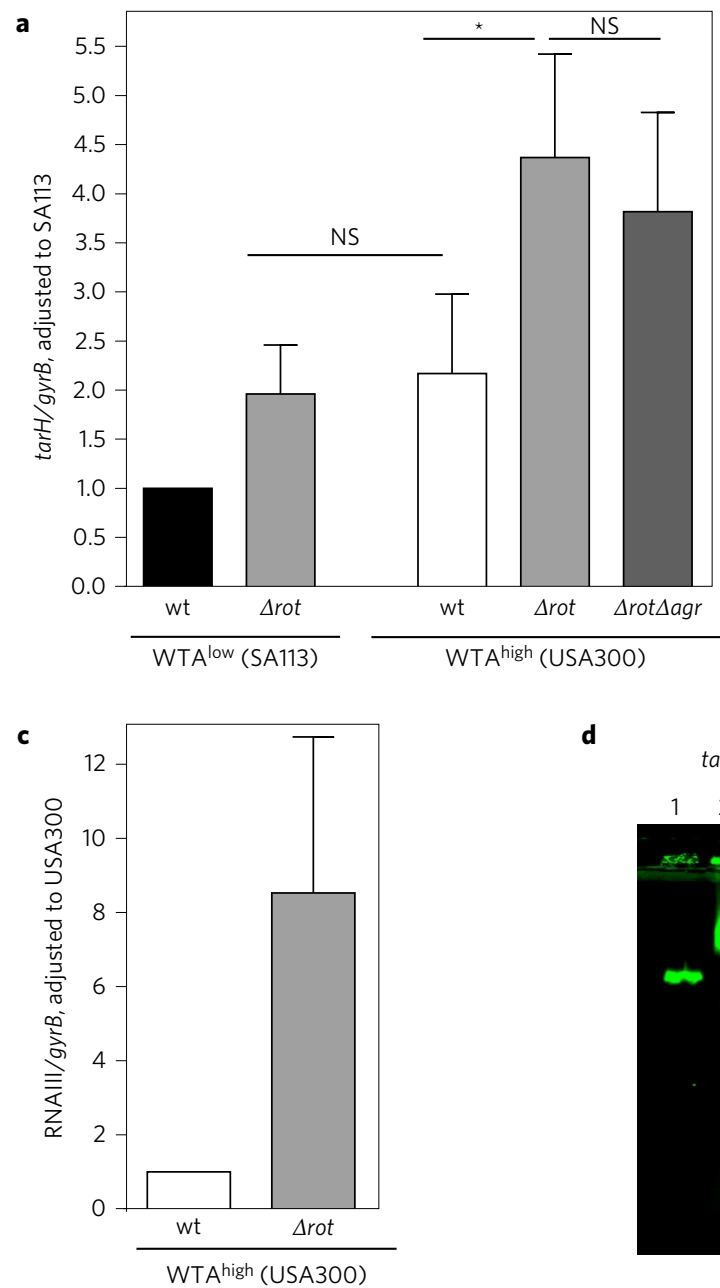

d
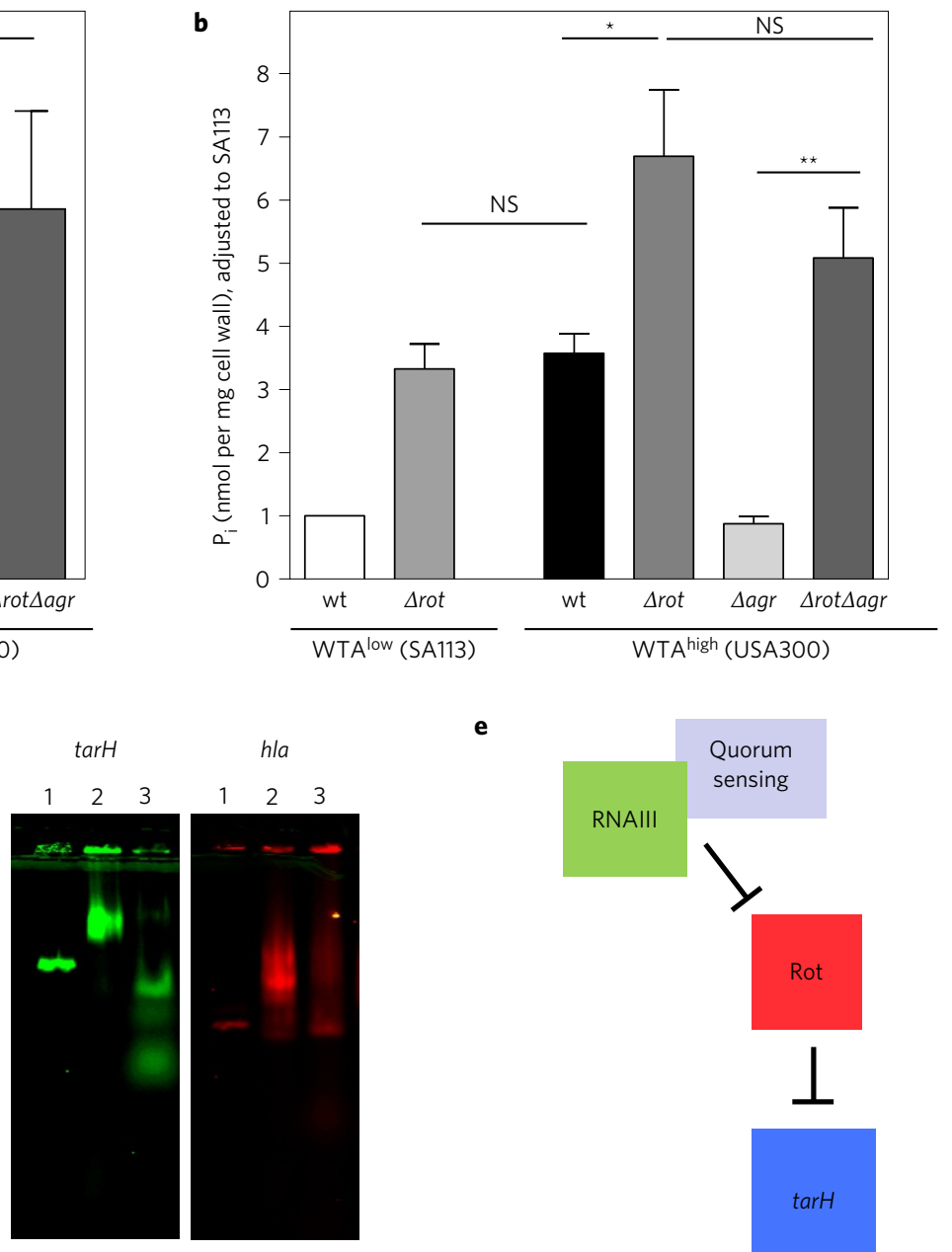

e

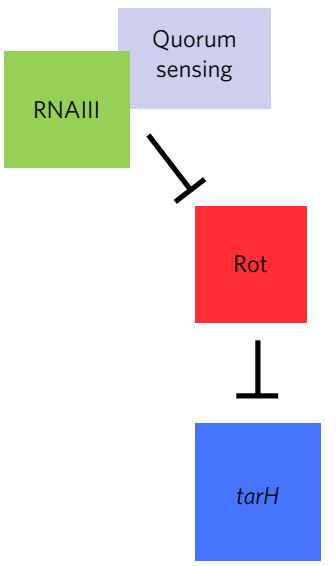

Figure 3 | Rot controls tarH expression and WTA biosynthesis downstream of RNAIll. a, Transcription analysis of the WTA biosynthesis gene tarH from in vitro cultures grown to stationary phase. Expression of transcripts was quantified relative to the transcription of gyrase (copies of tarH per copy of $g y r B$ ) and adjusted to SA113 (expression of SA113 in each independent experiment was set to 1). Shown are means \pm s.e.m., $n=8$ independent experiments. $P$ values for multiple comparisons were determined by one-way ANOVA with Bonferroni's post-test. ${ }^{\star} P<0.05$. $\mathbf{b}$, Content of WTA in the cell wall of WTA high

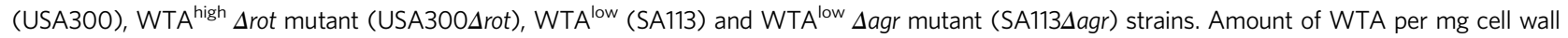
preparation was determined with a colorimetric assay (WTA amount is depicted as nmol inorganic phosphorus $\left(\mathrm{P}_{\mathrm{i}}\right)$ per mg cell wall dry weight) and adjusted to SA113 (WTA amount of SA113 in each independent experiment was set to 1). Shown are means \pm s.e.m., $n=6$ independent experiments. $P$ values for multiple comparisons were determined by one-way ANOVA with Bonferroni's post-test. ${ }^{\star} P<0.05$, ${ }^{\star \star} P<0.01$. c, Transcription analysis of RNAlll in WTA ${ }^{\text {high }}$ and WTA ${ }^{\text {high }} \Delta$ rot S. aureus in stationary-phase cultures. Expression of the RNAlll transcript was quantified relative to the transcription of gyrase (copies of RNAlll per copy of gyrB) and adjusted to wt WTA ${ }^{\text {high }}$. Shown are means \pm s.e.m., $n=8$ independent experiments. d, LI-COR Odyssey-based gelshift assays with cell extracts and tarH promoter (green). Rot binding to the promoter was visualized with cell extracts from a Rot-expressing USA300 strain lacking agr (lane 2) and an isogenic rot mutant (lane 3). Lane 1 contains the promoter fragment without cell extract as a control. The hla promoter (red) was used as a positive control. Rot binding to the hla promoter was visualized with cell extracts from a Rot-expressing USA300 strain lacking agr (lane 2) and an isogenic rot mutant (lane 3). Lane 1 contains the promoter fragment without cell extract as a control. Shown is a representative example of $n=3$ independent experiments. e, The tarH regulatory cascade; tarH is under negative control of a repressor termed 'repressor of toxins' (Rot). Rot mRNA stability is controlled by RNAIII and at high RNAIll levels Rot-mediated repression is relaxed.

Transcriptional control of tarH by the repressor of toxins, a major downstream regulator of the Agr system. The repressor of toxins (Rot) is a major effector downstream of $\operatorname{agr}^{56}$ and acts as a transcriptional regulator of an array of genes. Rot mRNA stability is negatively affected by RNAIII and therefore RNAIII mediates derepression of Rot-regulated genes ${ }^{57}$. When we measured tarH expression in WTA $\mathrm{Wigh}^{\text {hig }}$ and ${ }^{\text {low }}$ wt and rot mutants, we found a significant impact of rot on tarH expression (Fig. 3a). In fact, a WTA ${ }^{\text {low }}$ rot mutant exhibited the same $\operatorname{tarH}$ expression level as a WTA ${ }^{\text {high }}$ wt. In addition, the rot mutation alleviated the strong decrease of tarH expression found in an agr mutant (see Fig. 2). In fact, the rot agr double mutant exhibited similarly elevated levels of tarH expression as a rot mutant alone.
When we measured the amounts of WTA in the cell walls of $\mathrm{WTA}^{\text {high }}$ and WTA ${ }^{\text {low }}$ wt and rot mutants (Fig. 3b), we found that WTA amounts correlated with a rot-dependent tarH expression pattern. A WTA ${ }^{\text {low }}$ rot mutant exhibited an elevated amount of WTA that was comparable to the WTA amount detected in a WTA ${ }^{\text {high }}$ wt. The rot mutation increased the WTA amounts in the WTA ${ }^{\text {high }}$ background even further, and in a rot agr double mutant the agr mutation phenotype was completely alleviated. Interestingly, when we measured RNAIII levels in the WTA $^{\text {high }}$ background in the wt and rot mutant we found that the absence of rot severely increased the levels of RNAIII (Fig. 3c). This indicates a direct interplay between rot mRNA and RNAIII and an altered steady state for RNAIII when Rot is missing. To 

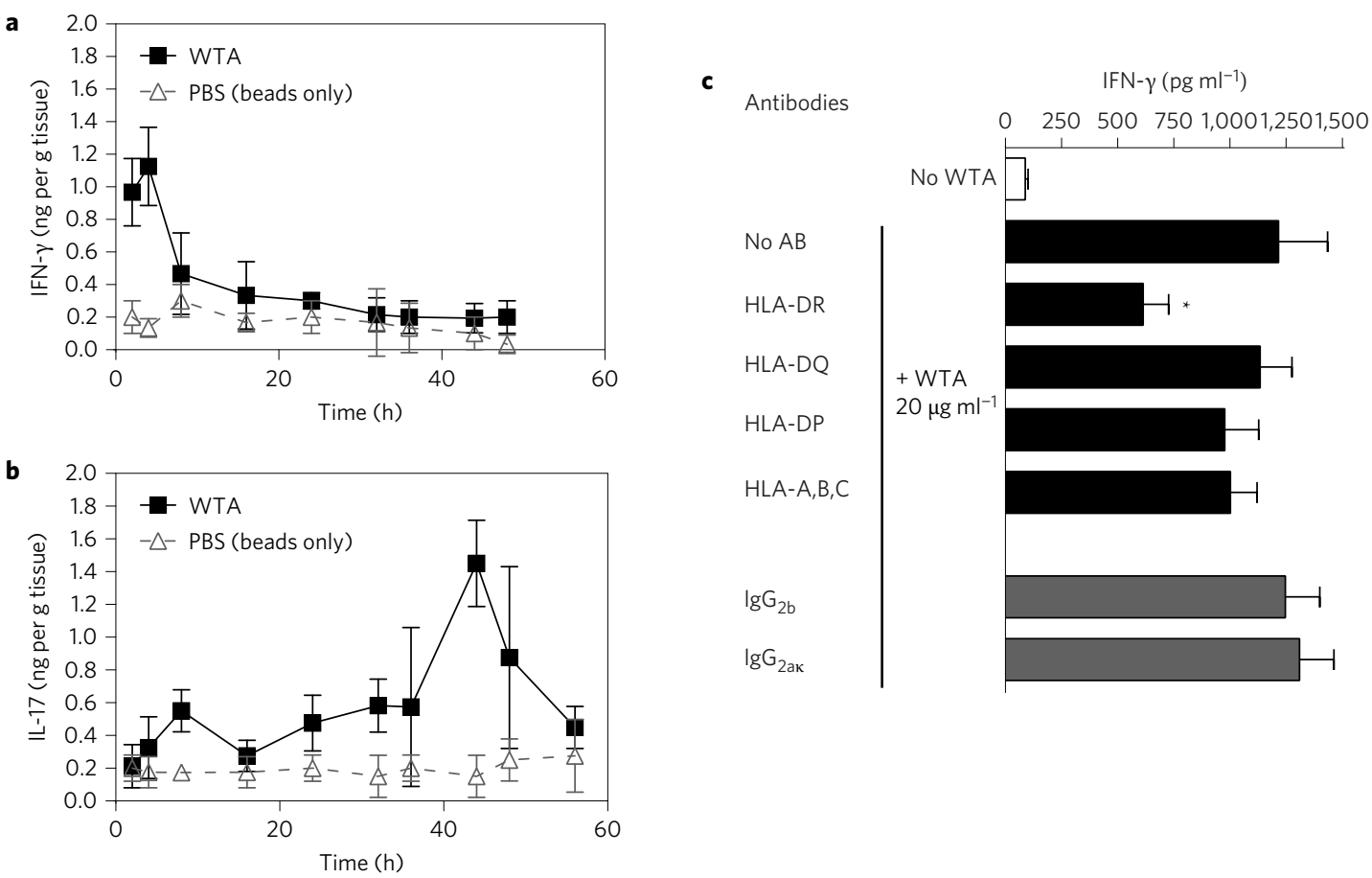

Figure 4 | MHC II-dependent cytokine secretion of WTA-stimulated T cells during skin abscess formation. a,b, Skin abscesses were induced by injecting $20 \mu \mathrm{g}$ of purified wt S. aureus WTA mixed with cytodex beads into the flanks of mice. Abscesses were excised, and the amounts of IFN- $\gamma$ per gram of abscess tissue (a) and IL-17 per gram of abscess tissue (b) were measured by ELISA; $n=6$ (three mice per time point with two abscesses per mouse). For controls dextran beads in PBS without WTA were used. Results are expressed as means \pm s.d. c, WTA activates human T cells to produce IFN- $\gamma$ in an MHC II-dependent mechanism. Total mononuclear cells, such as APCs, were pre-incubated with blocking Abs $\left(2 \mu \mathrm{g} \mathrm{ml} \mathrm{I}^{-1}\right)$ to the MHC II molecules HLA-DR, HLA-DP and HLA-DQ or MHC I molecules HLA-A, HLA-B and HLA-C and appropriate isotype control Abs for $1 \mathrm{~h}$ before the addition of CD4 ${ }^{+} \mathrm{T}$ cells. Co-cultures of the APCs $\left(1 \times 10^{5}\right)$ and CD4 ${ }^{+}$T cells $\left(1 \times 10^{5}\right)$ were then stimulated with $20 \mu \mathrm{g} \mathrm{ml}^{-1}$ WTA for $72 \mathrm{~h}$. IFN- $\gamma$ levels in the supernatants were then quantified by ELISA. The HLA-DR Ab significantly reduced IFN- $\gamma$ production. Results are expressed as means \pm s.e.m. for $n=6$ independent experiments. $P$ values for comparisons with no Ab were determined by one-way ANOVA with Dunnett's post-test. ${ }^{\star} P<0.05$.

demonstrate Rot binding to the tarH promoter region we performed gel-shift assays (Fig. 3d). Cell extracts from a Rot-expressing strain (in the USA300 agr mutant to ensure high Rot levels) mediated a clear shift of the promoter fragment when run in an agarose gel, while a cell extract from an isogenic strain lacking Rot was not able to mediate such a shift and the promoter fragment was partially degraded. A promoter fragment of the hla gene, which is Rotrepressed $^{59}$, was used and showed a similar shift.

In addition, when we measured WTA expression over time (Supplementary Fig. 7), we found that WTA amounts increased during logarithmic growth and peaked in the stationary growth phase. In line with an RNAIII and rot-dependent mechanism, this effect was more pronounced in a WTA ${ }^{\text {high }}$ wt strain when compared to a $\mathrm{WTA}^{\text {low }}$ strain, and the WTA ${ }^{\text {high }}$ phenotype only became evident at the onset of the stationary phase. Taken together, we conclude a regulatory cascade that involves high RNAIII levels, a more efficient Rot mRNA degradation and thus a more efficient Rot derepression on the tarH promoter level than the molecular mechanism behind the WTA ${ }^{\text {high }}$ phenotype (Fig. 3e).

Overexpression of tarH in $\mathrm{WTA}^{\text {low }}$ strains can restore the WTA $^{\text {high }}$ phenotype. We hypothesized that high tarH expression leads to the WTA ${ }^{\text {high }}$ phenotype due to increased translocation of WTA molecules. We therefore tested whether the WTA ${ }^{\text {high }}$ phenotype could be restored in $\mathrm{WTA}^{\text {low }}$ strains by overexpressing the tarH gene in WTA ${ }^{\text {low }}$ strain SA113 from the plasmid vector 474 (Supplementary Fig. 8). The tarH gene was put under the control of a promoter encoded on plasmid pRB474 (Supplementary Table 1). Overexpression of $\operatorname{tarH}$ in the WTA ${ }^{\text {low }}$ (SA113 pRB474+ tarH) strain indeed induced the WTA ${ }^{\text {high }}$ phenotype (Fig. 2b).
As indicated above, tarH gene expression in $\mathrm{WTA}^{\text {high }} \Delta$ agr mutants was reduced to the level of WTA ${ }^{\text {low }}$ strains. We therefore used the tarH overexpression vector in WTA ${ }^{\text {high }} \Delta a g r$ mutants $(103 \Delta a g r$ pRB474+tarH, MW2 $\Delta a g r$ pRB474+tarH, USA3004agr pRB474 + tarH) and were able to restore the $\mathrm{WTA}^{\text {high }}$ phenotype. In contrast, transformation with the empty plasmid pRB474 (SA113 pRB474, 331865 pRB474, 103 4 agr pRB474, MW2 $4 a g r$ pRB474, USA3004agr pRB474) did not affect WTA levels in any $S$. aureus strain (Fig. 2b).

WTA induces interferon- $\gamma$ at the onset of skin abscess formation and IL-17 at the late stages of abscess formation. We have seen before that self-clearing, non-lesion-forming subcutaneous abscesses, induced by WTA, depend on $\mathrm{CD}^{+} \mathrm{T}$ cells ${ }^{51}$, and we wanted to elucidate the hallmark cytokines involved in this process. Abscess formation was induced by injecting WTA mixed with cytodex beads into the flanks of mice. We measured interferon- $\gamma$ (IFN- $\gamma$ ) and interleukin 17 (IL-17) production in the abscess by enzyme-linked immunosorbent assay (ELISA) at different time points (Fig. 4) and detected strong IFN- $\gamma$ production only in the very early phases of abscess formation (Fig. 4a), while IL-17 showed only weak production at early time points (Fig. 4b) and peaked at later time points that coincided with abscess clearing.

We have seen before that mouse and human $\mathrm{T}$ cells are activated by WTA-presenting APCs (antigen-presenting cells) in an MHC II-dependent manner ${ }^{51}$. To demonstrate the MHC II dependency of the IFN- $\gamma$ response after WTA-induced $\mathrm{CD}^{+}{ }^{+} \mathrm{T}$ cell (human $\mathrm{T}$ cells) activation in vitro, we tested whether IFN- $\gamma$ production could be inhibited in the presence of blocking 
a

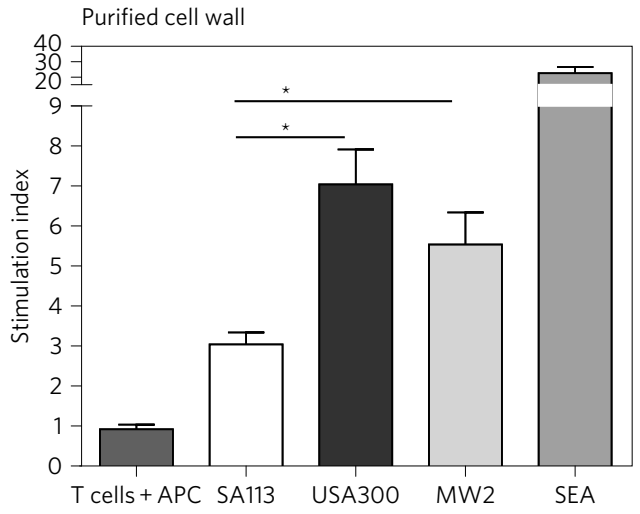

b

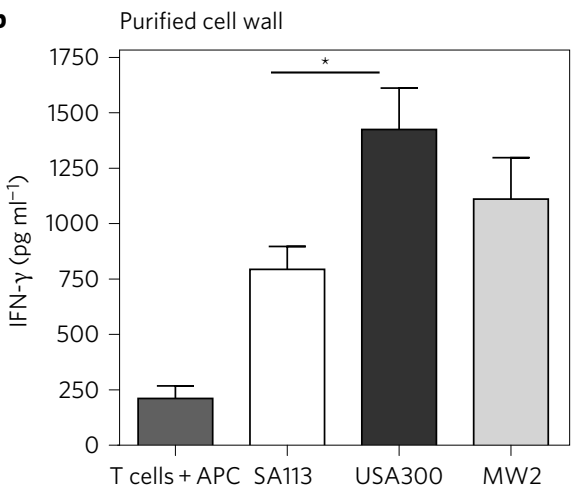

c Purified cell wall

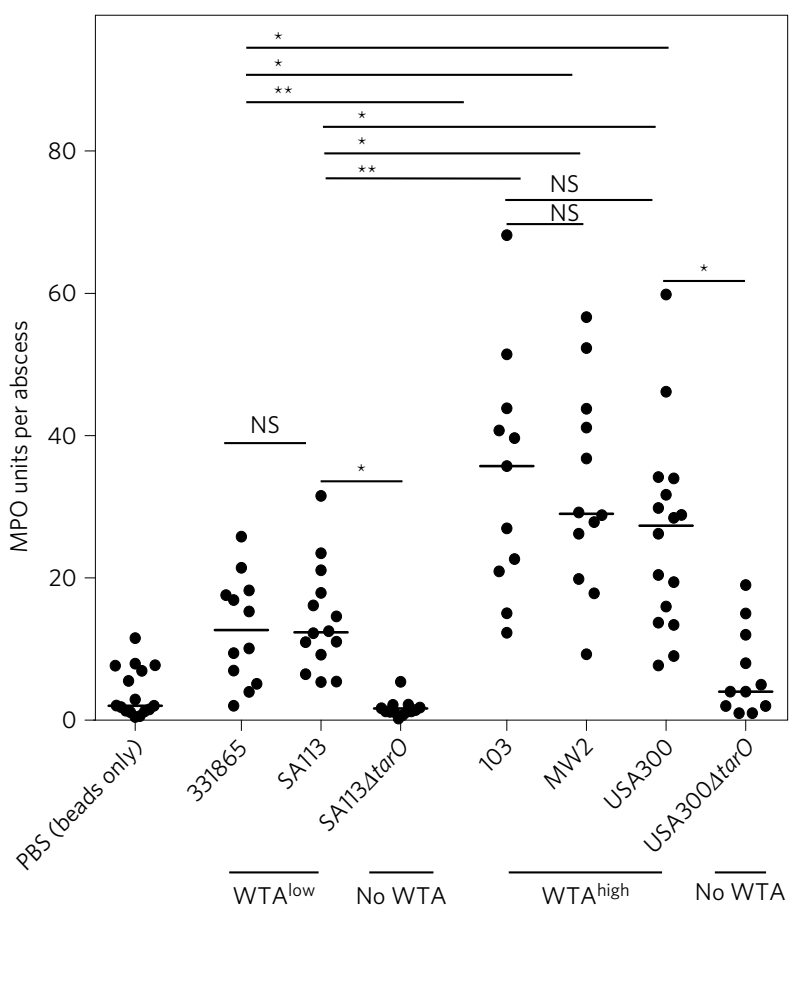

Figure 5 | Induction of T-cell-dependent IFN- $\boldsymbol{\gamma}$ secretion and abscess formation by cell wall fractions. $\mathbf{a}$, T cell proliferation assay with highly pure, protein-free cell wall fractions. Cell wall fractions isolated from highly pathogenic CA-MRSA strains (MW2, USA300) were incubated with APCs $\left(1 \times 10^{5}\right)$ and T cells $\left(2 \times 10^{5}\right)$ for 6 days. S. aureus enterotoxin A (SEA) was used as a positive control $\left(2 \mathrm{ng} \mathrm{ml}^{-1}\right)$. Cell wall fractions from CA-MRSA strains (MW2, USA300) induce T cell proliferation more efficiently than cell wall fractions from MSSA and the laboratory S. aureus strain SA113. Results are expressed as means \pm s.e.m. for $n=5$ independent experiments. $P$ values for comparisons with SA113 were determined by one-way ANOVA with Dunnett's post-test. ${ }^{\star} P<0.05$. b. Measurement of T-cell-dependent IFN- $\gamma$ expression. A T cell proliferation assay with cell wall fractions was performed. Cell wall fractions isolated from MW2 and USA300 (CA-MRSA) induce T-cell-dependent IFN- $\gamma$ expression more efficiently than cell wall fractions from SA113 (MSSA, laboratory strain) $(n=5)$. T cells and APCs were incubated with cell wall preparations for $72 \mathrm{~h}$. IFN- $\gamma$ secretion was determined by ELISA. Results are expressed as the means \pm s.e.m. for $n=5$ independent experiments. $P$ values for comparisons with SA113 were determined by one-way ANOVA with Dunnett's post-test. ${ }^{\star} P<0.05$. c) Abscess formation induced by cell wall fractions monitored via a myeloperoxidase (MPO) assay. Cell wall fractions from the CA-MRSA strains USA300, MW2 and the superantigen-free clinical isolate 103 induce abscesses more efficiently than cell wall fractions from laboratory strain SA113 and superantigenfree clinical isolate 331865. MPO is a marker of inflammation in abscess tissue. Twenty micrograms of cell wall were injected into the flanks of mice, and abscesses were extracted. MPO activity was measured in an enzymatic assay. Shown is a dot-blot with medians, with each dot representing a single abscess (two abscesses per mouse). $P$ values for multiple comparisons were determined by one-way ANOVA with Bonferroni's post-test. ${ }^{\star} P<0.05,{ }^{\star \star} P<0.01$.

antibodies (Abs) against the MHC II molecules HLA-DR, HLA-DP and HLA-DQ or the MHC I molecules HLA-A, HLA-B and HLA-C and isotype control Abs. We were able to inhibit IFN- $\gamma$ production significantly by adding an HLA-DR blocking Ab (Fig. 4c). Antibodies to HLA-DP, HLA-A, HLA-B or HLA-C and their respective isotype controls showed no effect. The experiment revealed that WTA activates human T cells to produce IFN- $\gamma$ via an MHC II-dependent mechanism.

Cell wall fractions from highly pathogenic WTA $^{\text {high }}$ strains induce $T$ cell proliferation, IFN- $\gamma$ secretion, and skin abscess formation more efficiently than cell wall fractions isolated from WTA $^{\text {low }}$ strains. To compare the ability of highly pure, protein-free cell wall fractions isolated from the pathogenic CA-MRSA strains MW2 and USA300 and a less virulent methicillin-sensitive Staphylococcus aureus (MSSA) laboratory strain (SA113) to activate $\mathrm{T}$ cells and induce IFN- $\gamma$ production, we cultured human $\mathrm{CD}^{+} \mathrm{T}$ cells with irradiated APCs and cell wall fractions. Cell wall fractions from CA-MRSA strains MW2 and USA300 provoked stronger T cell proliferation (Fig. 5a) and induced stronger IFN- $\gamma$ secretion than cell wall fractions from the laboratory strain SA113 (Fig. 5b).
We then tested the ability of purified cell wall fractions to induce abscess formation in mice. Protein-free, highly pure cell wall fractions were derived from the highly virulent CA-MRSA strains MW2, USA300, the superantigen-free clinical isolate 103, as well as the less virulent $S$. aureus strains SA113 and 331865 (superantigen-free clinical isolate), and were used in a skin abscess mouse model. Abscess-inducing activity was quantified by measuring neutrophil accumulation at the infection site with a myeloperoxidase (MPO) assay ${ }^{51}$. Cell wall fractions from highly virulent (WTA ${ }^{\text {high }}$ ) $S$. aureus strains induced strong MPO activity, whereas cell wall fractions from the less virulent (WTA ${ }^{\text {low }}$ ) S. aureus isolates were significantly less active (Fig. 5c). To test whether WTA amounts alone affect the induction of abscess formation, we injected different amounts of purified WTA and found that MPO activity indeed depends on the amount of WTA injected subcutaneous (s.c.) into the flanks of mice (Supplementary Fig. 9). To exclude the possibility that WTA tailoring modifications ${ }^{58}$ (D-ala, GlcNAc) contribute to cell-wall-mediated abscess formation, we assessed the expression of the $d l t$ operon, which is responsible for WTA D-alanylation ${ }^{59}$, and the two $\mathrm{N}$-acetylglucosaminyl-transferases (TarM and TarS), which are responsible for WTA modification with $\alpha$ - or $\beta$-GlcNAc, 
a

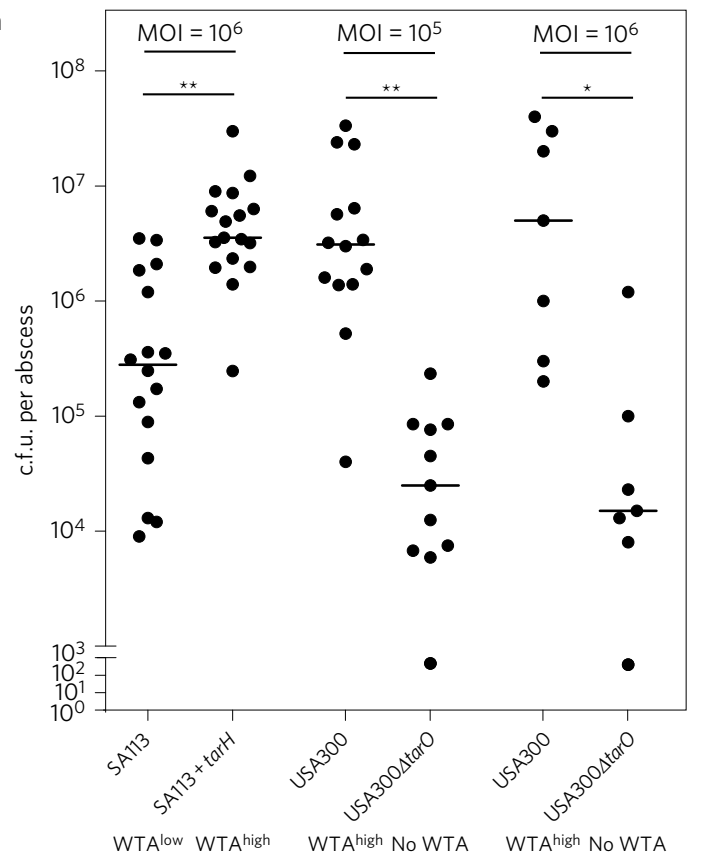

b

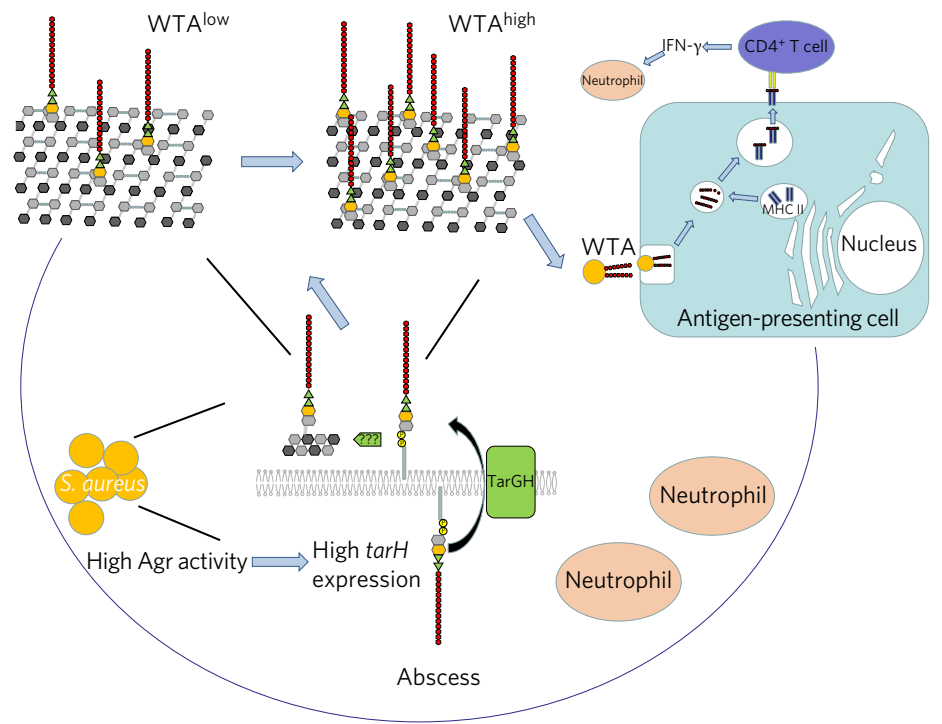

Figure 6 | Skin abscess formation with whole bacterial cells and model for WTA-mediated strain-specific virulence. a, To induce abscess formation, $10^{6}-10^{5}$ colony-forming units (c.f.u.) of living bacterial cells (S. aureus SA113 (WTA ${ }^{\text {low }}$ ), SA113 pRBtarH (tarH overexpression plasmid which facilitates a WTA $^{\text {high }}$ phenotype), USA300 (WTA ${ }^{\text {high }}$ ) and USA300 $\Delta$ tarO (lacks all WTA)) were mixed with cytodex beads and injected s.c. into the flanks of mice. After $48 \mathrm{~h}$, the mice were euthanized, and each abscess was excised, homogenized and cultured quantitatively. In the case of USA300, we found dermonecrosis at a higher multiplicity of infection $\left(\mathrm{MOI}\right.$ of $10^{6}$ ) and therefore included an $\mathrm{MOI}$ of $10^{5}$ where defined abscesses can be excised. Shown is a dot-blot with medians, with each dot representing a single abscess (two abscesses per mouse). Pairwise $P$ values were determined by $t$-test with Welch correction. ${ }^{\star} P<0.05,{ }^{\star}{ }^{*} P<0.01$. b, Model for the impact of WTA on strain-specific virulence. In CA-MRSA, cell WTA incorporation into the peptidoglycan is significantly elevated. This WTA ${ }^{\text {high }}$ phenotype depends on the specific upregulation of tarH expression by the global virulence regulator Agr, which exhibits intrinsically high activity in CA-MRSA. WTA ${ }^{\text {high }}$ cell walls are able to stimulate T-cell-dependent IFN- $\gamma$ production at the onset of abscess formation more efficiently than cell walls with lower WTA amounts. This mechanism plays an important role in modulation of early abscess development.

respectively ${ }^{60}$ (Supplementary Figs 1 and 2). We could detect differences in the expression of the GlcNAc transferases in the tested strains (Supplementary Fig. 10). WTA ${ }^{\text {low }}$ strain SA113 exhibited expression of both tarM (Supplementary Fig. 10a) and tarS (Supplementary Fig. 10b) expression. Compared to SA113 and another HA-MRSA, WTA ${ }^{\text {low }}$ strain (USA500), the WTA $^{\text {high }}$ strain USA300 clearly exhibited elevated levels of tarM mRNA (Supplementary Fig. 10a). All three strains also exhibited tarS expression (elevated in USA300 only). In contrast, MW2 (WTA $^{\text {high }}$ ) showed very low tarM mRNA levels and moderate tarS levels. Strains 331865 (WTA ${ }^{\text {low }}$ ) and 103 (WTA ${ }^{\text {high }}$ ) only expressed tarS in considerable amounts (Supplementary Fig. 10b), but tarS mRNA levels were severely decreased compared to SA113. In line with these results, USA 300 exhibited a slightly, albeit not statistically significant, increased amount of GlcNAc in its WTA when compared to SA113, while 331865 and 103 showed very low GlcNAc levels (Supplementary Fig. 11). We then assessed the impact of WTA GlcNAc modification on abscess formation. To that end, we compared cell wall fractions isolated from USA300 wt and an isogenic mutant lacking both TarM and TarS in the s.c. abscess model (Supplementary Fig 12). We could not detect a significant impact on abscess induction when both GlcNAc modifications were missing from WTA. In addition, WTA ${ }^{\text {low }}$ cell wall isolated from an HA-MRSA strain (USA500) exhibited a significantly lower abscess-inducing capacity when compared to USA300 cell wall. When we compared whole, live bacteria in the abscess model (Supplementary Fig. 13), we again detected no significant phenotype in the tarM/S mutant, while the WTA ${ }^{\text {low }}$ strain USA500 was clearly a less efficient abscess inducer. In addition, when we injected purified WTA together with live bacterial cells of the two WTA ${ }^{\text {low }}$ strains SA113 and USA500
(HA-MRSA), the colony-forming units (c.f.u.) recovered after $48 \mathrm{~h}$ were significantly increased and the $\mathrm{WTA}^{\text {low }}$ strains exhibited a phenotype that was comparable to USA300 (CA-MRSA). With respect to $\mathrm{D}$-alanine modifications, we could not detect differences in the expression of the dlt operon (Supplementary Fig. 10c), nor in the D-alanine levels of isolated WTA (Supplementary Fig. 11), from all tested strains.

Overexpression of $\operatorname{tarH}$ in $\mathrm{WTA}^{\text {low }}$ strains increases the ability to induce skin abscess formation, comparable to $\mathrm{WTA}^{\text {high }}$ strain USA300. Finally, we compared the ability of strain SA113, with and without the $\operatorname{tar} H$ overexpression plasmid (which leads to a WTA $^{\text {high }}$ phenotype), to induce abscess formation (Fig. 6a). When we used whole bacterial cells in the s.c. abscess model, the $\operatorname{tar} H$ plasmid-harbouring strain demonstrated an increased capacity to induce abscess formation. This was in line with the elevated abscess induction observed with USA300. To test if WTA has an impact on abscess formation in the highly pathogenic USA300 background, we used an isogenic mutant lacking all WTA molecules (USA3004tarO). This mutant exhibited a significantly reduced ability to induce abscess formation when compared to the WTA ${ }^{\text {high }}$ wt USA300. Furthermore, when we overexpressed tarH in an additional WTA ${ }^{\text {low }}$ strain background (HA-MRSA USA500), we could again detect an increased ability to induce s.c. abscesses in the flanks of mice (Supplementary Fig. 14).

\section{Discussion}

Here, we have demonstrated a novel role for the zwitterionic cell wall polymer WTA in $S$. aureus strain-specific virulence. Our data indicate that increased expression of the late-phase WTA biosynthesis gene $\operatorname{tar} H$ leads to a WTA ${ }^{\text {high }}$ phenotype in CA-MRSA, 
which is characterized by significantly elevated amounts of WTA in the cell wall. Surprisingly, we found that the WTA ${ }^{\text {high }}$ phenotype exhibited by CA-MRSA is connected to the quorum sensing system Agr. It has been reported previously that this global virulence regulator system is highly active in CA-MRSA strains ${ }^{22,28,61}$. Indeed, we found highly active Agr in all WTA ${ }^{\text {high }}$ strains, while WTA ${ }^{\text {low }}$ strains showed weak Agr activity or even a functionally inactive agr regulon. In WTA ${ }^{\text {high }}$ strains an excess of WTA in the cell wall is achieved by Agr-dependent over-expression of a tarH that encodes a possible bottleneck enzyme in WTA biosynthesis. The mature WTA polymer is exported by the TarG/H transporter and TarH constitutes the energizing ATPase unit of the ABC transporter. The coupling of tarH overexpression and transporter activity is currently under investigation in our laboratory. Evidence for Agrmediated control of WTA polymer length has been reported by Meredith and colleagues ${ }^{62}$. However, we could not detect differences in polymer length when we compared the WTA ${ }^{\text {high }}$ and WTA ${ }^{\text {low }}$ strains analysed here. Interestingly, screening for late-stage WTA biosynthesis inhibitors in large compound libraries ${ }^{45,63,64}$ only identified TarG inhibitors, indicating again that WTA precursor export might be the rate-limiting step in the pathway. Furthermore, we demonstrate here for the first time that Agr control of WTA biosynthesis is mediated by Rot, an important repressor of several Agr targets ${ }^{65}$. The Agr effector RNAIII has been demonstrated to decrease rot mRNA stability and efficiently reduce Rot-mediated repression ${ }^{66}$. A defined consensus sequence for Rot binding in promoter regions of Rot-controlled genes has not been identified ${ }^{67}$. However, Rot seems to exhibit high affinity to AT-rich promoter regions ${ }^{67}$. In fact, the tarH promoter region is AT-rich, arguing for Rot-dependent control of the tarH promoter (Supplementary Fig. 15). In whole-cell lysates (in agr-negative background to ensure high Rot levels) of isogenic rot wt and mutant we could detect binding of Rot to the tarH promoter region. Our analysis clearly indicates that the WTA ${ }^{\text {high }}$ phenotype is mediated by high RNAIII levels, which facilitate a more efficient Rot derepression in WTA $^{\text {high }}$ strains. In line with this explanation of strain-specific differences, we found that in a WTA ${ }^{\text {low }}$ strain, which is a functional agr mutant (SA113), mutation of rot leads to tarH expression levels and WTA amounts that are comparable to WTA ${ }^{\text {high }}$ strains. Measuring WTA levels over time we found that the WTA amounts for WTA ${ }^{\text {high }}$ and WTA ${ }^{\text {low }}$ strains only started to differ significantly at the onset of the stationary growth phase. We conclude that in agr mutants or low Agr-activity isolates, Rot activity is not decreased at the onset of the stationary phase as much as in WTA ${ }^{\text {high }}$ isolates. In addition, we detected a strong increase in the RNAIII level when we mutated rot in the WTA ${ }^{\text {high }}$ background, indicating an altered steady state of RNAIII amounts. These results are in line with a more efficient, RNAIII-mediated, Rot derepression in WTA ${ }^{\text {high }}$ strains.

We have shown before that WTA is able to activate $\mathrm{CD} 4^{+} \mathrm{T}$ cells in an MHC II-dependent manner, which modulates the early development of skin abscesses in a mouse model ${ }^{51}$. Consequently, the increased amounts of WTA render the cell wall of CA-MRSA more immunologically active. In line with these findings, abscess induction correlated with the amount of WTA incorporated in the cell wall of $S$. aureus strains. This phenotype probably depends on the ability of WTA ${ }^{\text {high }}$ cell wall fractions to induce $\mathrm{CD}^{+} \mathrm{T}$ cell proliferation and IFN- $\gamma$ secretion more efficiently than $\mathrm{WTA}^{\text {low }}$ cell walls. This is in line with a recent study reporting that WTA-specific T cells can be detected in healthy humans ${ }^{68}$, with a sub-fraction of these WTA-specific T cells exhibiting a robust IFN- $\gamma$ response. In contrast, other reports implicate IL-17-producing $\gamma \delta \mathrm{T}$ cells and TH17-dependent responses in controlling mouse ${ }^{69}$ or rabbit $^{70}$ cutaneous $S$. aureus infection at the innate stage. However, the authors either studied dermonecrotic lesions and not defined skin abscesses, or monitored later time points. When we injected purified WTA mixed with cytodex beads s.c. into the flanks of mice, we detected only a weak peak of IL-17 in the early phases of abscess formation. The primary IL-17 peak occurred at later time points that coincided with abscess clearing. The earliest relevant cytokine we detected in this model was IFN- $\gamma$, which peaks early, even before IL-17 could be detected. In addition, abscess induction with WTA did not lead to severe necrotic skin lesions but to a self-clearing, defined abscess. Thus, we conclude that WTA modulates the very early phases of skin abscess formation by a $\mathrm{CD}^{+} \mathrm{T}$ cell- and IFN- $\gamma$-dependent mechanism, while IL-17-dependent mechanisms play a host-protective role at later time points and contribute to the clearing of the abscess and wound healing. Another study provided evidence for a host protective role of IL-17/TH17 responses and an anti-protective role for IFN- $\gamma /$ TH1 responses in $S$. aureus skin infections ${ }^{71}$, arguing for an active role of $S$. aureus in early abscess formation as a mechanism supporting immune evasion. High WTA amounts might permit $S$. aureus to amplify early mechanisms of abscess formation, thereby creating a microenvironment that protects bacteria from host responses. In line with this idea, overexpression of $\operatorname{tar} \mathrm{H}$ in a $\mathrm{WTA}^{\text {low }}$ strain (SA113), which turned the strain into a WTA ${ }^{\text {high }}$ strain, led to increased abscess-inducing activity (Fig. 6a). More strikingly, we could increase abscess formation and c.f.u.s in the abscess by injecting purified WTA together with the bacterial inoculums of WTA ${ }^{\text {low }}$ strains USA500 and SA113 (Supplementary Fig. 13). USA500 is a strong toxin producer, and the fact that purified WTA alone allows USA500 to reach higher c.f.u.s in the abscess clearly underlines that WTA and toxins play different roles in the process of abscess formation. We also tested the impact of important WTA tailoring modifications D-alanine and GlcNAc and could not detect differences in D-alanylation between the WTA ${ }^{\text {high }}$ and WTA ${ }^{\text {low }}$ strains. The GlcNAc tailoring modification was slightly increased in USA300; however, when we compared the wt to an isogenic tarM/S mutant that lacks all GlcNAc modifications, we could not detect a significant phenotype in the s.c. mouse model of abscess formation.

Taken together, we conclude that overexpression of WTA biosynthesis is a mechanism that certain CA-MRSAs exploit to gain virulence (Fig. 6b). Recent advances in the development of antimicrobial substances led to the conclusion that WTA is an ideal target for novel anti-infective strategies ${ }^{42}$ and antibiotics ${ }^{43,44}$, and we believe that our report will aid in the development of novel anti-staphylococcal strategies that can be especially helpful in combating highly virulent CA-MRSA.

\section{Methods}

Bacterial strains and growth conditions. The bacterial strains, plasmids and oligonucleotides used in this study are described in Supplementary Table 1. S. aureus strains were cultivated in B-Medium (for cell wall or WTA isolation and infection experiments) or in TSB (tryptic soy broth) medium (Difco Laboratories) and incubated at $37^{\circ} \mathrm{C}$ with shaking. Resistant $S$. aureus were cultivated in media supplemented with appropriate antibiotics (tetracycline $\left(5 \mu \mathrm{g} \mathrm{ml}^{-1}\right)$ or chloramphenicol $\left.\left(10 \mu \mathrm{g} \mathrm{ml}^{-1}\right)\right)$. All strains were kept on blood agar plates to monitor toxin agr activity and toxin production.

Construction of agr deletion mutants. For deletion of agr (Supplementary Table 1), bacteriophage $\Phi 11$ containing $\operatorname{agr::tet}(M)$ was propagated in strain RN4220. Using standard methods, $\Phi 11$ was used to transduce agr::tet $(M)$ from RN6911 (ref. 32) to different target strains. In this construct, the entire agr locus, including agrDBCA and RNAIII, has been deleted ${ }^{32}$. The deletion of $a g r$ was confirmed by PCR and transcription analysis (primer rnaIIIfor and rnaIIIrev).

Construction of a recombinant expression vector (pRB474) for tarH with Gibson cloning. The open reading frame of $\operatorname{tar} H$ was amplified and cloned into expression vector pRB474 using a modified Gibson cloning protocol ${ }^{72}$. Wild-type $\operatorname{tarH}$ gene was amplified by PCR (primers gib_pRB474_tarH_for and gib_pRB474_tarH_rev) from the genomic DNA of the corresponding strains. Oligonucleotide sequences are provided in Supplementary Table 1. Vector pRB474 was amplified by PCR with primers gib_pRB474_f and gib_pRB474_r to generate tarH insert overhangs. Vector and insert PCR products were digested for $1 \mathrm{~h}$ at $37^{\circ} \mathrm{C}$ with $10 \mathrm{U}$ of DpnI. Each of 
the DpnI-digested DNA samples $(1 \mu \mathrm{l})$ was added to $15 \mu \mathrm{l}$ of the Gibson master mix and incubated for $45 \mathrm{~min}$ at $50{ }^{\circ} \mathrm{C}$. Gibson reaction mix (pRB474+tarH, $5 \mu \mathrm{l}$ ) was used to transform $50 \mu \mathrm{l}$ of chemo-competent Escherichia coli DC10B or DH5a cells.

PAGE analysis of WTA. For PAGE analysis of WTA samples, a $26 \%$ and 0.75 -mm-thick resolving gel was cast, as described recently ${ }^{62}$. WTA samples $(100 \mathrm{nmol}$ of phosphate per lane) were loaded onto gels and resolved for $24 \mathrm{~h}$ using a constant current of $40 \mathrm{~mA}$ per gel. WTA bands were visualized using the Alcian blue silver staining method. Briefly, the gels were fixed and stained with $0.005 \%$ (wt/vol) Alcian blue in EAW solution ( $40 \%$ ethanol and $5 \%$ acetic acid in water) at room temperature for several hours until the WTA ladder became visible. To intensify the staining pattern, the Bio-Rad silver stain kit (Bio-Rad) was used according to the manufacturer's instructions after oxidation of the gels with $0.7 \% \mathrm{NaIO}_{4}$ for $20 \mathrm{~min}$.

Cell wall and WTA isolation and polymer analysis. Cell wall and WTA were isolated as described previously $y^{38}$. The instruments and devices used in the isolation process were depyrogenated by heat inactivation for $4 \mathrm{~h}$ at $240{ }^{\circ} \mathrm{C}$. Bacteria were grown overnight in B-medium, supplemented with $0.2 \%$ glucose. WTA and cell wall extraction for immunological assays and in vivo experiments were performed on a large scale with a Euler cell mill (Euler) and a mini scale for WTA quantification with a FastPrep-24 Instrument (MP Biomedicals). Cell lysates were incubated overnight with DNase I (40 units $\mathrm{ml}^{-1}$, Roche) and RNase A (80 units $\mathrm{ml}^{-1}$, Sigma) at $37^{\circ} \mathrm{C}$ and 200 r.p.m. followed by a proteinaseK digest ( 80 units per g cell wall, Applichem). Cell wall and WTA were dialysed against pyrogen-free water (Ambion). WTA amounts were quantified by determining the inorganic phosphate $\left(\mathrm{P}_{\mathrm{i}}\right)$ content, as described previously $y^{38,58}$.

D-Alanylation and GlcNAc amounts for the WTA polymers were quantified as described previously 73,74 .

Purified, pyrogen-free cell wall and WTA for immunological assays and in vivo experiments were analysed for endotoxin with the Limulus amoebocyte lysate test (Charles River Laboratories), for protein via ultraviolet absorbance at $280 \mathrm{~nm}$, for SDS-PAGE electrophoresis with silver stain, and for nucleic acids by agarose gel electrophoresis or a PicoGreen assay.

Gel shift assays with $\operatorname{tarH}$ promoter. Whole-cell protein extracts were prepared from over night cultures in TSB. Cells were washed in tris-EDTA buffer and lysed in a buffer containing $10 \mathrm{mM}$ Tris, $1 \mathrm{mM}$ EDTA, $50 \mathrm{mM} \mathrm{KCl}, 5 \mathrm{mM} \mathrm{MgCl}{ }_{2}$, $10 \%$ glycerol, $\mathrm{pH} 7.4$, as described in ref. 57, supplemented with dithiothreitol $(1 \mathrm{mM})$ and $1 \times$ complete proteinase inhibitor cocktail (Sigma). Protein extracts from isogenic strains with and without rot (all in agr-negative background to allow

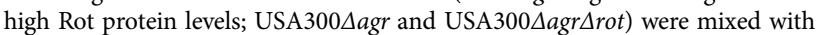
infrared-dye labelled promoter probes (PCR amplification with labelled primers (DY-701 for hla and DY-781 for rot) purchased from Biomers GmbH, Supplementary Table 1) for tarH and hla (positive control) and incubated for $20 \mathrm{~min}$ at room temperature. The probes were $355 \mathrm{bp}(\operatorname{tarH})$ and $299 \mathrm{bp}$ (hla). Samples were directly run on a $3 \%$ agarose gel and imaged on a LI-COR Odyssey system with settings for $700 \mathrm{~nm}$ emission (hla promoter) and $800 \mathrm{~nm}$ (rot promoter).

Mouse model of subcutaneous abscess formation. Male Swiss Webster ND4 mice (4-6 weeks old) were obtained from Harlan. In the subcutaneous abscess model, $20 \mu \mathrm{g} / 100 \mu \mathrm{l}$ purified cell wall WTA or live whole bacterial cells (as indicated in the figure legends) were mixed with equal volumes of sterile dextran beads (Cytodex 1, Sigma), and the mixture $(0.2 \mathrm{ml})$ was injected into each flank of the mouse as described previously $y^{75}$. For controls, equal volumes of PBS were mixed with dextran beads. After $48 \mathrm{~h}$, mice were euthanized, and the abscesses were excised and homogenized in $1 \mathrm{ml}$ PBS (Gibco by Life Technologies) for c.f.u. determination or in $500 \mu \mathrm{l}$ extraction buffer $^{76}$ for MPO measurement or cytokine determination. MPO is present in the azurophilic granules of neutrophils and is routinely used to assess inflammatory responses in tissues ${ }^{77}$ as well as abscess formation. Measurements of single cytokines were performed, for example with mouse IL-17 and IFN- $\gamma$ Quantikine ELISA Kits (R\&D Biosystems). MPO activity was determined with a colorimetric assay ${ }^{76}$ and was used as a quantitative measure of neutrophil infiltration. For assays where we injected purified WTA we screened for the production of a number of different cytokines by ELISA (R\&D Systems Quantikine) at early $(2 \mathrm{~h})$ and late phases $(48 \mathrm{~h})$ at $20 \mu \mathrm{g}$ per abscess (Supplementary Fig. 16a). While large amounts of IFN- $\gamma$ were measurable very early, IL-17 production was primarily observed at later stages of abscess formation. We then elucidated the production of IFN- $\gamma$ and IL-17 over time and in more detail. For c.f.u. counts, MPO measurements und cytokine assays, each abscess was treated as an independent $n$, as described previously (two abscesses per mouse).

T cell activation and IFN- $\gamma$ cytokine production assay. Mononuclear cells were purified by density gradient centrifugation in Polymorphoprep (Axis-Shield) from blood drawn from different healthy human donors. $\mathrm{CD} 4^{+} \mathrm{T}$ cells were purified with $\mathrm{CD}^{+}$MACS enrichment columns (Milteny). Then, $2 \times 10^{5} \mathrm{~T}$ cells per ml were co-cultured with $1 \times 10^{5}$ irradiated APCs per $\mathrm{ml}$ and purified S. aureus cell wall $\left(50 \mu \mathrm{g} \mathrm{ml}^{-1}\right)$, which was the optimal amount, as determined from titration experiments (Supplementary Fig. 16b). S. aureus enterotoxin A (SEA) $\left(2 \mathrm{ng} \mathrm{ml}^{-1}\right)$ was used as a positive control, and T cells co-cultured with APCs alone were used as negative controls. Proliferation was assayed with a carboxyfluorescein succinimidyl ester dilution assay by fluorescence-activated cell scanning. The $\mathrm{T}$ cell stimulation index was calculated by normalizing to wells with APCs and T cells but no stimulating antigen. After stimulation, supernatants were collected by centrifugation $\left(300 \mathrm{~g}, 10 \mathrm{~min}, 4^{\circ} \mathrm{C}\right.$ ) and stored at $-80^{\circ} \mathrm{C}$ until IFN- $\gamma$ was assayed by ELISA (R\&D Biosystems) according to the manufacturer's instructions. Blocking antibodies were used in some experiments to evaluate the impact of HLA on WTA-dependent IFN- $\gamma$ production. The antibodies used were HLA-DR clone L243 (Abcam), HLA-DQ clone SPV-L3 (Abcam), HLA-DP clone 1E3 Abnova, HLA-A,B,C clone W6/32 (Biolegend) and the isotype controls IgG2b clone 20116 (R\&D Systems) and IgG2a clone ICIGG2A (Abcam).

RNA isolation in vitro and qRT-PCR. For RNA isolation, bacteria were grown overnight in TSB medium to the stationary growth phase (optical density at $600 \mathrm{~nm}\left(\mathrm{OD}_{600}\right)$ of 10-14), and $1 \mathrm{ml}$ was collected by centrifugation for $3 \mathrm{~min}$ at 10,000 r.p.m. and $4{ }^{\circ} \mathrm{C}$. Bacteria were mechanically disrupted in $1 \mathrm{ml}$ TRIzol reagent (Invitrogen/Life Technologies) with $0.5 \mathrm{ml}$ zirconia-silica beads (diameter of $0.1 \mathrm{~mm}$, Carl-Roth) in a high-speed homogenizer (FastPrep-24 Instrument, MP Biomedicals). RNA was further isolated as described in the manual provided by the manufacturer. Primers (obtained from Metabion) used for qRT-PCR are shown in Supplementary Table 1 and were designed using Primer3web (http://bioinfo.ut.ee/ primer3). qRT-PCR was carried out using Brilliant II SYBR Green 1-Step Master Mix (Agilent). Relative quantifications were performed with a LightCycler480II instrument (Roche)

The transcriptional levels of target genes ( $\operatorname{tar} \mathrm{O} / \mathrm{A} / \mathrm{K} / \mathrm{L} / \mathrm{G} / \mathrm{H} / \mathrm{M} / \mathrm{S}$, dlt operon, rot, RNAIII) were normalized against the expression of $g y r \mathrm{~B}$ as an internal control and in some assays normalized to expression in WTA ${ }^{\text {low }}$ strain SA113.

Ethics statement. Animal experiments were performed in strict accordance with the German regulations of the Society for Laboratory Animal Science (GV-SOLAS) and the European Health Law of the Federation of Laboratory Animal Science Associations (FELASA). The protocol was approved by the Regierungspräsidium Tübingen (permit no. H2/10). Human blood was collected from healthy volunteers who gave written informed consent for venipuncture in accordance with protocols approved by the University of Tübingen, Germany.

Statistical analysis. Statistical analyses were performed with Graphpad Prism (GraphPad Software, version 5.04) using appropriate statistical methods as indicated in the figure legends. $P$ values $\leq 0.05$ were considered significant. For all experiments $n$ refers to the number of independent experiments (except for animal studies, where $n$ refers to a single abscess, as described previously ${ }^{51}$ ). In all experiments, two technical replicates were used unless noted otherwise. For animal studies we used SPSS Sample Power V.3 or G-Power 3.1 to estimate the group size required for statistical significance. Power calculations were performed without assumption of a normal distribution and we used Wilcoxon-Mann-Whitney to evaluate the sample size for a first-degree error of 0.05 and a second degree error of 0.2 . We did not fully blind or randomize animal experiments.

Data availability. The data that support the findings are available from the corresponding author upon request.

Received 25 April 2016; accepted 28 November 2016; published 23 January 2017; corrected 13 March 2017

\section{References}

1. DeLeo, F. R., Otto, M., Kreiswirth, B. N. \& Chambers, H. F. Communityassociated meticillin-resistant Staphylococcus aureus. Lancet 375, 1557-1568 (2010).

2. Stryjewski, M. E. \& Chambers, H. F. Skin and soft-tissue infections caused by community-acquired methicillin-resistant Staphylococcus aureus. Clin. Infect. Dis. 46(Suppl. 5), S368-S377 (2008).

3. Fridkin, S. K. et al. Methicillin-resistant Staphylococcus aureus disease in three communities. N. Engl. J. Med. 352, 1436-1444 (2005).

4. Purcell, K. \& Fergie, J. Epidemic of community-acquired methicillin-resistant Staphylococcus aureus infections: a 14-year study at Driscoll Children's Hospital. Arch. Pediatr. Adolesc. Med. 159, 980-985 (2005).

5. Hulten, K. G. et al. Three-year surveillance of community onset health careassociated Staphylococcus aureus infections in children. Pediatr. Infect. Dis. J. 25, 349-353 (2006).

6. Liu, C. et al. A population-based study of the incidence and molecular epidemiology of methicillin-resistant Staphylococcus aureus disease in San Francisco, 2004-2005. Clin. Infect. Dis. 46, 1637-1646 (2008).

7. Mediavilla, J. R., Chen, L., Mathema, B. \& Kreiswirth, B. N. Global epidemiology of community-associated methicillin resistant Staphylococcus aureus (CA-MRSA). Curr. Opin. Microbiol. 15, 588-595 (2012).

8. Macal, C. M. et al. Modeling the transmission of community-associated methicillin-resistant Staphylococcus aureus: a dynamic agent-based simulation. J. Transl. Med. 12, 124 (2014). 
9. Moran, G. J. et al. Methicillin-resistant S. aureus infections among patients in the emergency department. N. Engl. J. Med. 355, 666-674 (2006).

10. Baker, P., Cohen, B., Liu, J. \& Larson, E. Incidence and risk factors for community-associated methicillin-resistant Staphylococcus aureus in New York City, 2006-2012. Epidemiol. Infect. 144, 1014-1017 (2016).

11. Como-Sabetti, K. et al. Community-associated methicillin-resistant Staphylococcus aureus: trends in case and isolate characteristics from six years of prospective surveillance. Public Health Rep. 124, 427-435 (2009).

12. Foster, T. J. Immune evasion by staphylococci. Nat. Rev. Microbiol. 3, 948-958 (2005).

13. Rooijakkers, S. H., van Kessel, K. P. \& van Strijp, J. A. Staphylococcal innate immune evasion. Trends Microbiol. 13, 596-601 (2005).

14. Otto, M. Basis of virulence in community-associated methicillin-resistant Staphylococcus aureus. Annu. Rev. Microbiol. 64, 143-162 (2010).

15. Voyich, J. M. et al. Insights into mechanisms used by Staphylococcus aureus to avoid destruction by human neutrophils. J. Immunol. 175, 3907-3919 (2005).

16. Moran, G. J., Amii, R. N., Abrahamian, F. M. \& Talan, D. A. Methicillin-resistant Staphylococcus aureus in community-acquired skin infections. Emerg. Infect. Dis. 11, 928-930 (2005).

17. King, M. D. et al. Emergence of community-acquired methicillin-resistant Staphylococcus aureus USA 300 clone as the predominant cause of skin and softtissue infections. Ann. Intern. Med. 144, 309-317 (2006).

18. Melles, D. C. et al. Panton-Valentine leukocidin genes in Staphylococcus aureus. Emerg. Infect. Dis. 12, 1174-1175 (2006)

19. Voyich, J. M. et al. Is Panton-Valentine leukocidin the major virulence determinant in community-associated methicillin-resistant Staphylococcus aureus disease? J. Infect. Dis. 194, 1761-1770 (2006).

20. Bubeck Wardenburg, J., Bae, T., Otto, M., Deleo, F. R. \& Schneewind, O. Poring over pores: $\alpha$-hemolysin and Panton-Valentine leukocidin in Staphylococcus aureus pneumonia. Nat. Med. 13, 1405-1406 (2007).

21. Bubeck Wardenburg, J., Palazzolo-Ballance, A. M., Otto, M., Schneewind, O. \& DeLeo, F. R. Panton-Valentine leukocidin is not a virulence determinant in murine models of community-associated methicillin-resistant Staphylococcus aureus disease. J. Infect. Dis. 198, 1166-1170 (2008).

22. Otto, M. Community-associated MRSA: what makes them special? Int. J. Med. Microbiol. 303, 324-330 (2013).

23. Wang, R. et al. Identification of novel cytolytic peptides as key virulence determinants for community-associated MRSA. Nat. Med. 13, 1510-1514 (2007).

24. Kobayashi, S. D. et al. Comparative analysis of USA300 virulence determinants in a rabbit model of skin and soft tissue infection. J. Infect. Dis. 204, 937-941 (2011).

25. Berube, B. J., Sampedro, G. R., Otto, M. \& Bubeck Wardenburg, J. The psma locus regulates production of Staphylococcus aureus alpha-toxin during infection. Infect Immun. 82, 3350-3358 (2014).

26. Hanberger, H. et al. Increased mortality associated with methicillin-resistant Staphylococcus aureus (MRSA) infection in the intensive care unit: results from the EPIC II study. Int. J. Antimicrob. Agents 38, 331-335 (2011).

27. Inoshima, I. et al. A Staphylococcus aureus pore-forming toxin subverts the activity of ADAM10 to cause lethal infection in mice. Nat. Med. 17, 1310-1314 (2011).

28. Cheung, G. Y., Wang, R., Khan, B. A., Sturdevant, D. E. \& Otto, M. Role of the accessory gene regulator agr in community-associated methicillin-resistant Staphylococcus aureus pathogenesis. Infect. Immun. 79, 1927-1935 (2011)

29. Queck, S. Y. et al. RNAIII-independent target gene control by the agr quorumsensing system: insight into the evolution of virulence regulation in Staphylococcus aureus. Mol. Cell 32, 150-158 (2008).

30. Li, M. et al. Evolution of virulence in epidemic community-associated methicillin-resistant Staphylococcus aureus. Proc. Natl Acad. Sci. USA 106, 5883-5888 (2009).

31. Novick, R. P. \& Geisinger, E. Quorum sensing in staphylococci. Annu. Rev. Genet. 42, 541-564 (2008).

32. Novick, R. P. et al. Synthesis of staphylococcal virulence factors is controlled by a regulatory RNA molecule. EMBO J. 12, 3967-3975 (1993).

33. Bronesky, D. et al. Staphylococcus aureus RNAIII and its regulon link quorum sensing, stress responses, metabolic adaptation, and regulation of virulence gene expression. Annu. Rev. Microbiol. 70, 299-316 (2016).

34. Miller, L. G. et al. Clinical and epidemiologic characteristics cannot distinguish community-associated methicillin-resistant Staphylococcus aureus infection from methicillin-susceptible $S$. aureus infection: a prospective investigation. Clin. Infect. Dis. 44, 471-482 (2007).

35. Diep, B. A. et al. Complete genome sequence of USA300, an epidemic clone of community-acquired meticillin-resistant Staphylococcus aureus. Lancet 367, 731-739 (2006)

36. Thurlow, L. R. et al. Functional modularity of the arginine catabolic mobile element contributes to the success of USA300 methicillin-resistant Staphylococcus aureus. Cell Host Microbe 13, 100-107 (2013).
37. Weidenmaier, C. \& Peschel, A. Teichoic acids and related cell-wall glycopolymers in Gram-positive physiology and host interactions. Nat. Rev. Microbiol. 6, 276-287 (2008).

38. Weidenmaier, C. et al. Role of teichoic acids in Staphylococcus aureus nasal colonization, a major risk factor in nosocomial infections. Nat. Med. 10, 243-245 (2004).

39. Baur, S. et al. A nasal epithelial receptor for Staphylococcus aureus WTA governs adhesion to epithelial cells and modulates nasal colonization. PLoS Pathog. 10, e1004089 (2014).

40. Weidenmaier, C. et al. DltABCD- and MprF-mediated cell envelope modifications of Staphylococcus aureus confer resistance to platelet microbicidal proteins and contribute to virulence in a rabbit endocarditis model. Infect. Immun. 73, 8033-8038 (2005).

41. Weidenmaier, C. et al. Lack of wall teichoic acids in Staphylococcus aureus leads to reduced interactions with endothelial cells and to attenuated virulence in a rabbit model of endocarditis. J. Infect. Dis. 191, 1771-1777 (2005).

42. Lehar, S. M. et al. Novel antibody-antibiotic conjugate eliminates intracellular S. aureus. Nature 527, 323-328 (2015).

43. Ling, L. L. et al. A new antibiotic kills pathogens without detectable resistance. Nature 517, 455-459 (2015).

44. Santa Maria, J. P. Jr et al. Compound-gene interaction mapping reveals distinct roles for Staphylococcus aureus teichoic acids. Proc. Natl Acad. Sci. USA 111, 12510-12515 (2014)

45. Wang, H. et al. Discovery of wall teichoic acid inhibitors as potential anti-MRSA $\beta$-lactam combination agents. Chem. Biol. 20, 272-284 (2013).

46. Pasquina, L. W., Santa Maria, J. P. \& Walker, S. Teichoic acid biosynthesis as an antibiotic target. Curr. Opin. Microbiol. 16, 531-537 (2013).

47. Lee, S. H. et al. TarO-specific inhibitors of wall teichoic acid biosynthesis restore $\beta$-lactam efficacy against methicillin-resistant staphylococci. Sci. Transl. Med. 8, 329ra332 (2016).

48. Mann, P. A. et al. Chemical genetic analysis and functional characterization of staphylococcal wall teichoic acid 2-epimerases reveals unconventional antibiotic drug targets. PLoS Pathog. 12, e1005585 (2016).

49. Neuhaus, F. C. \& Baddiley, J. A continuum of anionic charge: structures and functions of D-alanyl-teichoic acids in Gram-positive bacteria. Microbiol. Mol. Biol. Rev. 67, 686-723 (2003).

50. Brown, S., Santa Maria, J. P. Jr \& Walker, S. Wall teichoic acids of Gram-positive bacteria. Annu. Rev. Microbiol. 67, 313-336 (2013).

51. Weidenmaier, C., McLoughlin, R. M. \& Lee, J. C. The zwitterionic cell wall teichoic acid of Staphylococcus aureus provokes skin abscesses in mice by a novel CD4+ T-cell-dependent mechanism. PLoS One 5, e13227 (2010).

52. Lazarevic, V. \& Karamata, D. The tagGH operon of Bacillus subtilis 168 encodes a two-component $\mathrm{ABC}$ transporter involved in the metabolism of two wall teichoic acids. Mol. Microbiol. 16, 345-355 (1995).

53. Schirner, K., Stone, L. K. \& Walker, S. ABC transporters required for export of wall teichoic acids do not discriminate between different main chain polymers. ACS Chem. Biol. 6, 407-412 (2011)

54. Bunce, C., Wheeler, L., Reed, G., Musser, J. \& Barg, N. Murine model of cutaneous infection with Gram-positive cocci. Infect. Immun. 60, 2636-2640 (1992).

55. Vuong, C., Gotz, F. \& Otto, M. Construction and characterization of an agr deletion mutant of Staphylococcus epidermidis. Infect. Immun. 68, 1048-1053 (2000).

56. Novick, R. P. Autoinduction and signal transduction in the regulation of staphylococcal virulence. Mol. Microbiol. 48, 1429-1449 (2003).

57. Killikelly, A. et al. Structure-based functional characterization of repressor of toxin (Rot). A central regulator of Staphylococcus aureus virulence. J. Bacteriol. 197, 188-200 (2015).

58. Rajagopal, M. \& Walker, S. Envelope structures of Gram-positive bacteria. Curr. Top. Microbiol. Immunol. http://dx.doi.org.10.1007/82_2015_5021 (2016).

59. Peschel, A. et al. Inactivation of the dlt operon in Staphylococcus aureus confers sensitivity to defensins, protegrins, and other antimicrobial peptides. J. Biol. Chem. 274, 8405-8410 (1999).

60. Winstel, V. et al. Wall teichoic acid glycosylation governs Staphylococcus aureus nasal colonization. mBio 6, e00632-15 (2015).

61. Montgomery, C. P., Boyle-Vavra, S. \& Daum, R. S. Importance of the global regulators Agr and SaeRS in the pathogenesis of CA-MRSA USA300 infection. PLoS One 5, e15177 (2010).

62. Meredith, T. C., Swoboda, J. G. \& Walker, S. Late-stage polyribitol phosphate wall teichoic acid biosynthesis in Staphylococcus aureus. J. Bacteriol. 190, 3046-3056 (2008)

63. Lee, K., Campbell, J., Swoboda, J. G., Cuny, G. D. \& Walker, S. Development of improved inhibitors of wall teichoic acid biosynthesis with potent activity against Staphylococcus aureus. Bioorg. Med. Chem. Lett. 20, 1767-1770 (2010).

64. Swoboda, J. G. et al. Discovery of a small molecule that blocks wall teichoic acid biosynthesis in Staphylococcus aureus. ACS Chem. Biol. 4, 875-883 (2009).

65. Geisinger, E., Adhikari, R. P., Jin, R., Ross, H. F. \& Novick, R. P. Inhibition of rot translation by RNAIII, a key feature of agr function. Mol. Microbiol. 61, 1038-1048 (2006). 
66. Boisset, S. et al. Staphylococcus aureus RNAIII coordinately represses the synthesis of virulence factors and the transcription regulator Rot by an antisense mechanism. Genes Dev. 21, 1353-1366 (2007).

67. Zhu, Y. et al. Structure of Rot, a global regulator of virulence genes in Staphylococcus aureus. Acta Crystallogr. D 70, 2467-2476 (2014).

68. Kolata, J. et al. The fall of a dogma? Unexpected high T cell memory response to S. aureus in humans. J. Infect. Dis. 212, 830-838 (2015).

69. Cho, J. S. et al. IL-17 is essential for host defense against cutaneous Staphylococcus aureus infection in mice. J. Clin. Invest. 120, 1762-1773 (2010).

70. Malachowa, N., Kobayashi, S. D., Sturdevant, D. E., Scott, D. P. \& DeLeo, F. R. Insights into the Staphylococcus aureus-host interface: global changes in host and pathogen gene expression in a rabbit skin infection model. PLoS One 10, e0117713 (2015).

71. Montgomery, C. P. et al. Protective immunity against recurrent Staphylococcus aureus skin infection requires antibody and interleukin-17A. Infect. Immun. 82, 2125-2134 (2014).

72. Gibson, D. G. et al. Enzymatic assembly of DNA molecules up to several hundred kilobases. Nat. Methods 6, 343-345 (2009).

73. Bertsche, U. et al. Increased cell wall teichoic acid production and D-alanylation are common phenotypes among daptomycin-resistant methicillin-resistant Staphylococcus aureus (MRSA) clinical isolates. PLoS One 8, e67398 (2013).

74. Smith, R. L. \& Gilkerson, E. Quantitation of glycosaminoglycan hexosamine using 3-methyl-2-benzothiazolone hydrazone hydrochloride. Anal. Biochem. 98, 478-480 (1979).

75. Portoles, M., Kiser, K. B., Bhasin, N., Chan, K. H. \& Lee, J. C. Staphylococcus aureus Cap5O has UDP-ManNAc dehydrogenase activity and is essential for capsule expression. Infect. Immun. 69, 917-923 (2001).

76. Mullane, K. M., Kraemer, R. \& Smith, B. Myeloperoxidase activity as a quantitative assessment of neutrophil infiltration into ischemic myocardium. J. Pharmacol. Methods 14, 157-167 (1985).
77. van der Veen, B. S., de Winther, M. P. \& Heeringa, P. Myeloperoxidase: molecular mechanisms of action and their relevance to human health and disease. Antioxid. Redox Signal. 11, 2899-2937 (2009).

\section{Acknowledgements}

The authors thank I. Autenrieth and A. Peschel for discussions and critical reading of the manuscript. This research was supported by grants from the German Research Foundation (SFB) to C.We. (SFB766 and TR34), C.Wo. (SFB766 and TR34) and B.M.B. (TR34). The funders had no role in the design of the experiments, in the collection, analysis and interpretation of the data, in writing the manuscript, or in the decision to submit the manuscript for publication.

\section{Author contributions}

S.W., C.Wo., J.K., B.M.B., J.S. and C.We. planned the experiments. S.W., J.S., N.W., D.Ke., L.K., J.B., T.G., V.W. and C.We. performed the experiments. C.Wo., J.K., B.M.B., V.W. and D.Kr. supplied materials and strains. S.W., J.S. and C.We. wrote the manuscript. All authors read and approved the final manuscript.

\section{Additional information}

Supplementary information is available for this paper.

Reprints and permissions information is available at www.nature.com/reprints.

Correspondence and requests for materials should be addressed to C.We.

How to cite this article: Wanner, S. et al. Wall teichoic acids mediate increased virulence in Staphylococcus aureus. Nat. Microbiol. 2, 16257 (2017).

\section{Competing interests}

The authors declare no competing financial interests. 


\section{Corrigendum: Wall teichoic acids mediate increased virulence in Staphylococcus aureus}

Stefanie Wanner, Jessica Schade, Daniela Keinhörster, Nicola Weller, Shilpa E. George, Larissa Kull, Jochen Bauer,

Timo Grau, Volker Winstel, Henriette Stoy, Dorothee Kretschmer, Julia Kolata, Christiane Wolz, Barbara M. Bröker and Christopher Weidenmaier

Nature Microbiology 2, 16257 (2017); published online 23 January 2017; corrected 13 March 2017

In the version of this Article originally published, the horizontal bars in Fig. 1a that indicate statistical differences were incorrectly placed. This has now been corrected in all versions of the Article, so that the horizontal bars indicate the statistical differences between strain 331865 and strains USA300, MW2 and 103. 